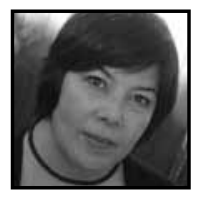

\title{
Fostering a Creativity Mindset for Teaching (and Learning)
}

\author{
Mia O'Brien, University of Queensland
}

\section{ABSTRACT}

Teaching is a creative practice that requires the kind of open-minded, whole-hearted, flexible, improvisational (yet knowledgeable), and performative orientation that I refer to as the "creativity mindset." Fostering such a mindset amongst preservice teachers can be challenging, since they often see their future teaching-selves as altruistic yet authoritarian subject matter experts. Underpinning these views are narrow conceptions of teaching, and of how we learn. To what extent can an experience of creative, performative pedagogy transform these views, and foster a creativity mindset for teaching (and learning) amongst preservice teachers?

\section{Introduction}

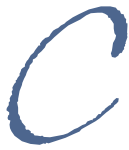

reativity remains a significant priority within education. The Organisation for Economic Co-operation and Development (OECD) has published reports on creativity and schools (1999); The National Advisory Committee on Creative and Cultural Education (NACCCE, 1999) signaled the importance of maintaining creativity within curriculum and pedagogy in schools across the United Kingdom; and within the recent return to a national approach the Australian Curriculum (ACARA, 2012) features creativity as a general capability to be cultivated within all subject areas.

In order for creativity to be a priority within schooling we need teachers who understand the nature of creativity and appreciate its pedagogical value. However, creativity is not usually high on the list of reasons for choosing teaching. In fact, those 
drawn to teaching often have stereotypically didactic views of teaching based on autobiographical experiences of the classroom (Lortie, 1975; Sfard \& Prusak, 2005). Indeed, some research indicates that commencing first year pre-service teachers choose teaching because they feel a) they are experts within particular subject areas, and hope to share that expertise with their future students; b) they are "fun" people to be with; and c) they envision their future teaching "selves" as friendly but informative authoritarian figures within a classroom (O'Brien \& Dole, 2012). More extensive psychometric studies (see Watt \& Richardson, 2012) illustrate the multidimensional nature of choosing teaching. These reasons include personal utilitarian motivations, intrinsic motivations, and ability-related beliefs. But such studies only serve to highlight our local experiences within teacher education programs. That is, when faced with visions of classrooms in which learning and teaching practices are represented as dialogic, inquiry-driven, creative practices-as opposed to the knowledge-heavy, didactic models of teaching and learning of personal visions-many preservice teachers feel challenged and uncomfortable (O'Brien, 2011, ATEA).

How do we effectively encourage preservice teachers to more readily embrace creativity as an important pedagogical process and agenda? In this study I was particularly interested in the perceptions and beliefs about learning and teaching that may be indicative of positive orientations towards the place of creativity in education. The aim was to foster a "creativity mindset" for teaching and learning.

\section{Creativity in Learning and Teaching Contexts}

Indeed, classrooms filled with dialogue, inquiry, collaboration, innovation, connectivity, and creative practices are the hallmarks of effective contemporary pedagogy (Gore, Griffiths, \& Ladwig, 2004; Lingard, Hayes, \& Mills, 2003), and not just the purview of creativity itself. So the pedagogical value of cultivating creativity in the classroom is well argued elsewhere (Jeffrey, 2008; Sawyer, 2012). What is missing however are more powerful conceptions of how teachers may adapt core beliefs or mindsets related to teaching, learning, and pedagogy in ways that more fully embrace the potential of creativity.

For example, there is general acknowledgement in the field that creativity, as it would be usefully applied to education, is not so much a fixed trait that an individual might possess, but rather a process of higher order thinking and engagement that is learnable by all (Craft, 2003; Jeffrey, 2008; McWilliam \& Haukkaa, 2008; Sawyer, 2012). This perspective disentangles creativity from the Arts and related notions of uncommon genius. Instead, creativity is conceptualized as a sustainable, replicable 
intellectual practice that transcends subject areas and informs innovation and knowledge growth (McWilliam \& Haukkaa, 2008). This view makes creativity an "ordinary" process that is generally accessible (Craft, 2003) and teachable (Jeffrey, 2008), and certainly well within the reach of the motivated teacher (Sawyer, 2012).

In fact, Sawyer (2012) reviewed a range of research that produced recommendations for building creativity in the classroom. His synthesis of the "teacher behaviours most commonly associated with creativity" (p. 4) include: i) openness of attitude and perspective, an inclusive classroom culture in which collaboration and the cross-fertilization of ideas is valued; ii) the deliberate cultivation of surprise and the unexpected as fruitful learning opportunities, that is closely coupled with iii) trust and a safe environment for risk-taking, in which time is allowed for thinking and incubation; iv) the development of students' self-efficacy; as well as v) support in the resistance to conformity of peers; vi) fostering of problem-finding, idea generation, questioning of assumptions, and imagination of alternative perspectives and viewpoints; based also on vii) the mastering of factual knowledge; viii) explicit modeling of creativity.

Jeffrey and Craft (2004) draw on extensive empirical research in their explications of creativity in education, and make a useful distinction between "teaching creatively" and "teaching for creativity." Teaching creatively involves the development of materials and approaches that foster students' interests and motivation in learning. In contrast, and of interest here, is the notion of "teaching for creativity" which relates to the forms of teaching that intend to develop students' own creative thinking and behavior. Teaching that develops creativity in students entails the development of the common capabilities and sensibilities of creativity (curiosity, creative processes and practices, etc.), the encouragement of young people to believe in their creative identities, as well as the development of a sense of agency and self-determination in the learning process.

Building on this work Jeffrey (2008) suggests that the characteristics of creative pedagogies include: the development of meaningful experiences that offer and reinforce social identities and roles for students; creative learning processes such as intellectual enquiry, possibility thinking, engagement with problems and a range of intelligences; and altered teaching and learning relationships (such as those that enable students to negotiate and/or lead learning).

The common thread across the discourse on creativity, teaching, and learning is that implementing creativity effectively within classroom contexts requires 
significant reframing of learners, learning, and teaching (Jeffrey, 2008; Jeffrey \& Craft, 2004; Sawyer, 2012). Sawyer (2012) suggests this is based on the differences between traditional views of classroom practices (instructionism) as opposed to more progressive, constructivist views of learning. Jeffrey and Craft (2004) hint at the need for inculcation into the values and principles of practice inherent within the creative process. Just as the foundation of creativity's place in education is anchored in a view of creativity as an emergent, tangible, replicable process of engagement-so too must the teaching of, and for, creativity be rooted in more fluid, flexible beliefs about how we learn and how we might teach.

Dweck's (1999) research on the relationship between personal beliefs and effectiveness or success seems particularly relevant here. In her work she makes a distinction between "fixed" mindsets and "growth" mindsets. People with fixed mindsets see their personal qualities (intelligence, talent, ability) as stable and unchangeable traits. Those with growth mindsets see such qualities as amenable and are thus more fluid in their view of learning and approach to life. A fluid or growth mindset seems particularly applicable to teaching for creativity. That is, teachers would need to see the qualities of their students and their personal teaching capabilities through a flexible, fluid lens in order to effectively facilitate creative pedagogical experiences. What might that mindset entail? How would we encourage its development?

\section{Drama, Storythread, and Improvised Pedagogy-An Intervention}

At the heart of this paper are the experiences of our pre-service teachers, documented as they participated in an extraordinary pedagogical event. Over the last two years a small contingent of our Bachelor of Education students have been invited to participate in, and observe, the unique educational adventure that is the Pullenvale Environmental Education Centre or PEEC (http://peec.org.au/). The PEEC offers a range of educational resources and support processes, but most significantly provides on-site learning experiences for primary or elementary school children from across the state. These learning experiences incorporate creative teaching strategies and in particular are anchored in the pedagogical practice of Storythread (Education Queensland, 1994). Storythread pedagogy aims to connect learners to real people, places, issues, and events, and to help them understand and apply curriculum content, through the use of story and drama, investigations, games and play, attentiveness, deep reflective responding, creative response and interpretive walks and engagement in the environment. A Storythread unit of learning begins with a story (often written and created by the teachers at PEEC) that captures a key issue in need of further exploration. At PEEC these stories are often based on environmental 
sustainability and/or the impact of human change on nature. Classroom teachers are provided with a range of preliminary resources and materials to introduce their students to the story, and they facilitate introductory and exploratory activities to build engagement in the story's themes over several weeks. This gives the students an opportunity to engage authentically and deeply with the issues at hand, and to build knowledge and understanding of the related curriculum content. Eventually, the students are able to "step into" the story as they attend an immersive excursion at PEEC, facilitated by the talented PEEC teachers who role play various characters and scenarios, and who over the course of the event engage the students in puzzling over and solving the particular dilemma or problem.

Storythread pedagogy has similarities to Scottish Storyline (Bell, Harkness, \& White, 2007) in that a) fictionalized stories are used/created to capture and represent curriculum content in its application to authentic social scenarios; that in turn b) act as stimuli for active learning processes that aim to enlarge and bring the concepts of note "to life" for students through the use of drama, role play, visual arts, inquiry, collaborative problem solving, and similar strategies over time; and therefore c) foreground the processes of active and inquiry learning as a pedagogical priority. In contrast, Storythread appears to distinguish itself from the Scottish Storyline approach by its emphasis on engaging students in extended dialogue and focused attentiveness activities, and in the case of PEEC, by its emphasis on the exploration of values related to the environment. The potential of these strategies for engaging even very young children in new levels of awareness and commitment to action shows much promise (Tooth \& Renshaw, 2012; Renshaw \& Tooth, 2009).

Importantly for this study, both Storythread and Scottish Storyline pedagogies recast the role of the teacher. As with many active learning pedagogies, teachers design active learning scenarios (set a context, provide potentially fruitful resources, design and sequence learning activities to engage students in various forms of investigations, etc.), and artfully facilitate emergent learning experiences (monitor and guide learning, whilst restraining from traditional forms of "content" delivery). These forms of pedagogy are highly dialogic, and require the kind of "improvisational" teaching that Sawyer (2004) refers to. Indeed, they require and perhaps epitomize Schön's notions of reflection-in-action (1983). In Storythread (and potentially in Scottish Storyline) pedagogies teachers do not provide students with extensive content, but rather engage and facilitate their students' search for information, scaffold and guide preliminary ideas, subtly sharpen and refine emerging understandings of content, and carefully navigate the development of values and potential action-all as part of the pedagogical process. It is this "shift" in pedagogical perspective (from content 
delivery to creative and active learning facilitator) that can be most challenging for preservice teachers. Few will have experienced the extensive use of story, drama, role-play, and fiction as mechanisms for engaging in curriculum content. And while many are keen to be "great" teachers who can motivate and inspire their students, most are unsure about how they can achieve this in a classroom setting. For these reasons I hoped that this intervention would effectively offset the sometimes didactic models of pedagogy our preservice teachers experience as university students, and that they would begin to comprehend the potential of more creative pedagogies within their own practice.

For the intervention, participating pre-service teachers were provided with a two-part experience. The first part entailed an all-day professional development workshop in which the staff at PEEC review and discuss their unique approach and the storythread pedagogy. This workshop covers and discusses the extensive range of supporting materials and educational resources that the centre develops and provides to schools. The second part involves a return visit to the PEEC Centre and an opportunity to observe and follow the activities of visiting school children as they participate in an all-day "in the story" experience. These follow-up sessions are typically five hours in length, and comprehensive in nature. Only two preservice teachers were permitted to attend any particular follow-up session as these days were primarily designed for visiting schools, and the presence of additional visitors needed to be minimized. These days proved invaluable as they provided a first-hand experience of the storythread pedagogy as it was implemented with up to 60 school children and their teachers/carers.

As part of the attendance requirements of the PEEC experience, all participating preservice teachers ( $n=24$ in 2011; $n=23$ in 2012) completed a short answer survey in which they were asked to self-report beliefs and perceptions related to learning, teaching, and their potential future self as teacher. The survey had a number of items, but I have selected items as having particular relevance to this paper's focus, including responses to themes such as:

- I see learning as...

- I describe myself as the kind of teacher who...

- $\quad$ A surprising or unexpected theme/idea/understanding I have taken from this experience is...

- $\quad$ This experience has helped me to... 
Responses to each item were collated and thematically analyzed (Flick, 2009). Soon after the PEEC experience the preservice teachers were required to complete an interview. Interviews were based on a simple schedule of themes that asked participants to report experiences and new understandings gleaned from the experience, and included questions such as:

- How did learning and teaching happen in this context?

- What surprised you most about learning and teaching in this experience?

- What is your understanding of learners and learning?

- $\quad$ Tell me about the teaching and learning practices that most impressed you and why?

The interviews were transcribed verbatim and a thematic analysis was undertaken to identify and illustrate the variation of responses to each question or theme.

\section{The Emerging Nature of a Creativity Mindset}

The overarching focus of this project was to track the impact of an intervention that enabled the preservice teachers to be explicitly trained in, and to observe the implementation of, a highly creative pedagogy. I hoped that this intervention would evoke transformation: an opening up of narrow views of learning and teaching. My hunch was that this experience would elicit new ways of thinking about learners and learning; teachers and teaching; the nature of pedagogy; and about themselves as future teachers. And that in turn, perhaps less directly, I felt preservice teachers would begin to orient towards the powerful potential of creativity in learning and teaching.

Just as such perceptions can be seen as indicators of shifting teacher identities, of "becoming pedagogical" (O'Brien et al., 2012), so too are they indicators of how our preservice teachers are orienting towards their future pedagogical self.

In this section I exemplify and discuss preservice teacher perceptions that emerged in relation to learning, teaching, and pedagogy, and frame them within the qualities of teaching for creativity that have been laid out in the recent literature.

\section{Views of Learning and Learners}

It is not uncommon for preservice teachers to assume that students learn through relatively passive processes in which the teacher, textbook, or some other external source provides the "knowledge" to be learned. While some hold more 
sophisticated views of learning in the broadest sense, most equate classroom or school-related learning with traditional models of instruction and simplistic learning theories (such as information processing and memory). At best, preservice teachers acknowledge that it is possible for learning to occur through creative means, but very few have direct experiences or in-depth understandings about how this might happen.

The PEEC intervention and in particular the experience of storythread and drama in pedagogy elicited broader views of the nature of learning. That is to say, the opportunity to observe that school students first had as they participated in roleplays and dramatized illustrations of various events, as well as in interpretive walks and guided attentiveness sessions seemed highly influential in broadening the preservice teachers' views of learning:

It was intriguing and interesting. I felt that it was the way most students learn. Children have more ways to learn other than from computers. Opportunities to learn never cease. (Chris, 2011)

I now see learning as an active participation in the process of pedagogy. (Eric, 2012)

I learned that in order to get kids to respect the environment, you can't just tell them that they should, they need to experience the environment and be in a place and be a part of it and then they will respect the environment and actually want to protect it and preserve it without having ideas forced upon them. (Beth, 2011)

For some preservice teachers these observations made them aware of assumptions they had made about learning and of what learning could entail:

I've always said it's a bad thing to assume you know what your students are thinking or learning, and this was sooo clear today. The kids I thought hated the day because they said this a number of times were actually the ones that had all the right answers at question time. So for me this demonstrates not only never assume but also knowledge and understanding can reach a child even if they are not "having fun" or rather they were having fun. (Loris, 2012)

Something we are constantly doing in all kinds of ways. You can learn things even when you don't realize you're learning! (Elizabeth, 2012) 
Others noted the significance of the students' agency and involvement in this pedagogical situation. As the PEEC teachers enacted various scenarios and invited the school students to join in "in character," the preservice students noted the potential power of storythread and drama to enable even very young students to engage and participate in their own way. To "invest" emotionally and intellectually:

[I was surprised at] how implicitly it can occur, and how the children's curiosity is a natural catalyst for learning and discovery. (Paige, 2012)

I was surprised at... That everyone can appreciate it in their own way. I spoke to a small group of boys who were hesitant to express their feelings to me, and the ways in which they would go about solving some problems in the Hoodwinked scenario because (and I'm only speculating, because I got the sense that this was the case...it certainly was when I was in grade 5!) they were "too cool" for the activities the rest of the class were participating in... but as time progressed they were completely engaged with the story and were enjoying themselves, and were subsequently some of the more active members in the discussions Lucinda facilitated. (Stephanie, 2012)

That it was not all directly linked to the topic/story of the day. The reflection of the grade 3 student who said she had learned such an amazing understanding of respect simply blew me away - that is, when asked what they has learned one particular little girl responded with some along the lines of "That when we treat people with respect and help them when they need help our friendship will go a long way." She was a grade 3 student! (Whitney, 2012)

What was most striking to the preservice teachers was the compelling nature of a creative pedagogy for engaging and holding the intellectual and emotional interests of the students. As the following extracts illustrate, the preservice teachers developed an emerging awareness of, and a renewed appreciation for, the impact of a meaningful learning experience that was at the same time comprehensively informative:

I think learning is a powerful tool in the lives of those who value it, and provides them with more opportunities to reach their potential in life. Even a basic understanding of certain ideas and concepts provides individuals with the capacity to question... and I think this is important in recognising your place in the world and how to prevail above any given situation. You can't let anyone other than yourself dictate your life-learning provides new experiences and the resources to allow individuals to make their own informed decisions. (Stephanie, 2012) 
The students' growing passion as they became more immersed in the activity-I think that by the end of it, they all had a pretty strong ecological identity and sense of right and wrong regarding the environment... they became more passionate, it was really lovely to see. (Stephanie, 2012)

These extracts illustrate significant shifts in the preservice teachers' views of learning and learners. These shifts reflect an emerging orientation to important aspects of creativity in learning and teaching. For example, their apprehension of the process of learning broadened and they became aware of the potential for learning to occur in the kind of "altered spaces" that Jeffrey (2008) describes. As the first few extracts indicate, the preservice teachers showed some surprise that learning could (and should) involve more than direct instructional methods (see particularly Chris, Eric, and Beth's comments), yet still include and creatively build on a strong foundation of knowledge (as Sawyer, 2012 has argued). We see glimmers of more complex understandings of learning as being driven by curiosity and personal engagement (much as Jeffrey \& Craft, 2004 have suggested). And as the last two extracts in this section indicate, the preservice teachers were deeply impressed by the genuine level of engagement and "passion" the students developed during the learning experience. Understanding the power that meaningful engagement as part of creative teaching and learning entails is a common thread in the literature (Craft, 2003; Jeffrey \& Craft, 2004; Sawyer, 2012).

\section{Views of Teaching and Teachers}

Just as the preservice teachers began to change their views about learning and learners, they also became explicitly aware of the well-crafted, deliberate practices of the PEEC teachers. They were impressed by the way in which simple classroom management strategies that were consistently integrated into the pedagogy were effective without stopping the flow of the activity.

At one level this shift was focused on the potential of employing interest and engagement for offsetting (or managing) the students' behavior:

There were few behavioral issues, and when there was the teacher simply found a moment to address it in a calm way. (Aisla, 2012)

The teachers' form of behavioural management-keeping the students engaged, and reinforcing the "RESPECT" high-5 thing; the children becoming so genuinely immersed in the learning. (Lorraine, 2012) 
But at another level the preservice teachers also became aware that teachers aim to do much more than just "teach the curriculum" and "control the class." They connect to what is interesting and relevant to students, provide safe learning environments, collaborate in the learning process, and direct their attention to facilitating connection and negotiated engagement (letting behavior management take care of itself):

Using a different approach such as this challenges students on many levels. What they learn is not just facts on paper, but also attitudes, problem solving, social and community involvement, and psychological development in learning behaviours. (Eric, 2012)

A teacher has to help the students want to learn - the teacher needs to engage with \& interest them (Elizabeth, 2012)

There is more to teaching than pedagogy, it is also about bringing together the students in a safe learning environment. (Felicia, 2012)

How involved the teachers got into the acting out of the story, but took a back seat when it came to behavior management. (Morag, 2012)

To use story telling excites children and extends their knowledge. The way the teacher excitedly engaged with students while upholding control. (Aisla, 2012)

Some preservice teachers were surprised and impressed by the deliberate positivity and enthusiasm for learning cultivated by the teachers. This is an important shift as many preservice teachers problematize the role of teachers and can easily feel too overwhelmed by various pressures and opt out of teaching creatively, or teaching for creativity. As this extract illustrates, the PEEC teachers modeled a highly positive learning relationship as well as some concrete strategies for engaging learners, which, in turn, inspired and influenced the preservice teachers:

The positive nature of the staff of PEEC. They were incredibly knowledgeable and positive about their work and it was a real pleasure and inspiration to work with educators who were so positively responsive to not only the students' experiences but ours as well. They had a solution for every problem. The value of their work at PEEC in many ways is so simple but so complex it was interesting to see how it had been overlooked in my own education at primary and high school (I never had an opportunity like this at school). (Loris, 2012) 
And as the following extract captures, the in-depth observation of teachers teaching creatively "in action" afforded some deeply impressive and long-lasting shifts in understanding the potential role, position, and relationship to students that teachers can cultivate:

[A surprising thing I noticed about teaching was] how to change the position of power in a classroom so that students are able to take control of their learning (and in that discover their own learning). (Beth, 2011)

These renewed views of teachers and teaching experienced by the preservice teachers reflect a growing awareness of creativity in teaching. These included many of the teacher behaviours commonly linked to creativity and learning synthesized by Sawyer (2012) and the characteristics of creative teaching outlined by Jeffrey (2008). These included: the development of trust, a sense of safety and self-efficacy for students (indicated here by Elizabeth, Felicia, and Morag); the modeling of positive and generative creative processes and behaviours (in Ailsa and Loris's comments); as well as a range of related cognitive, social, and emotional outcomes (outlined by Eric). Beth's comment is both indicative and significant. For a great majority of preservice teachers the greatest challenge to their emergent teaching identity and practice is the stubborn vision of teacher as "sage on the stage" - even those willing to consider alternative pedagogies struggle to see their roles and place as teacher. The extended observation of the PEEC teachers in action appeared to loosen these views significantly. Instead, we see evidence of the preservice teachers awareness of altered teaching and learning relationships (Jeffrey, 2008) and the understanding that in stepping aside from a "leadership" role per se, students could take control and discover their own learning.

\section{Views of Pedagogy}

Setting aside the complexities surrounding its meaning, I use the term pedagogy here to refer to the interrelationship and qualities of interaction that arise between teachers and students as they collaboratively navigate and negotiate the learning space. Just as our preservice teachers initially hold simplistic views of learning and perceptions of teaching as an authoritarian, instructional process, they assume pedagogy to be a highly didactic, linear, and structured relationship. The opportunity to observe teachers implementing creative, active learning forms of pedagogy certainly disrupted these assumptions, but in ways that seemed to enable the preservice teachers to readily embrace an alternative perspective and philosophy almost instantaneously. 
Storythread makes good use of narratives and the story-telling experience to engage students in some core concepts and life-like contexts. The teachers at PEEC also use storythread to set up generative, problem finding and problem "responding" learning scenarios. These often take the form of extended dialogues in which the PEEC teacher is "in character" and leads a discussion asking the students to solve a problem or generate some potential solutions. Our preservice teachers found the educational potential of this pedagogy to be highly illuminating and personally inspiring:

I believe narrative is a wonderful means of learning and combined with the other elements of Storythread Pedagogy (attentiveness and reflection) forms a powerful teaching tool. I'm a strong believer that learning needs to be situated in real-life contexts in order for it to be memorable, and that's exactly what Storythread aims to achieve. I also love the creative, hands-on elements behind it and would love to learn how to inspire my students to use their whole bodies when learning (e.g., full sensory, mind body engagement). (Anna, 2011)

[What surprised me was] the idea of creating that interesting way of teaching through stories and drama linking subjects together. (Nell, 2011)

[What surprised me was]...It turned learning into an adventure with the children the adventurers. (Whitney, 2012)

As these comments indicate, the preservice teachers began to more fully appreciate the potential of this pedagogy for establishing (as Jeffrey \& Craft, 2004; and Jeffrey, 2008 propose) relevance of meaning for both individual students and the group; ownership of knowledge; control of the learning process by students; and innovation and intellectual inquiry:

The excitement of the kids-it was almost tangible and certainly contagious (so perhaps they escalated because of me?) Arrival, entering the "rocket ship," meeting Arlec, in the forest while exploring and discovering new and interesting things...the level of excitement would not have veered below 8 out of 10 . (Paige, 2012)

Extended role-playing as they did with Hoodwinked; I had not anticipated that they would be effective with students as old as grade 5, anticipated that they would be made more apathetic by peer pressure-now that I know they can be engaged with this method I would definitely like to incorporate it. (Rachel, 2012) 
Shifting a person's perception, when you learn something, especially through experiencing it hands on. It is a journey, different for each person, individual, absorbing and using information at different paces and levels. And, the more tools, such as Storythread and Productive Pedagogies, a teacher can effectively and appropriately use, the better the student outcomes because they are engaged and connected with the topic and therefore more inclined to become active self-directed learners. (Paige, 2012)

The PEEC pedagogy incorporates notions of "deep attentiveness" based on the tenet that learning is driven by attention. In this process the students are taken to a place in the outdoors that is unfamiliar or new, and asked to sit in quiet stillness for between 1-5 minutes. Afterwards they take turns sharing a comment about what they noticed-an attentiveness statement. The power of "deep attentiveness" was felt by a majority of our preservice teachers, many of whom continued to reference this strategy in their learning journals for one of their courses. Eric's comment below captures this impression:

Using the magnifying glass to take photos of tiny flowers and berries (now in frames on my lounge room wall) and hearing the attentiveness statements read back to us. Experiencing the intricacies of the role play with the grade 5 students. I did not expect it to be so involved and to see how the students progressively got more involved in the story (even the difficult/skeptical students) was quite enlightening. (Eric, 2012)

For many of our preservice teachers, they found the incorporation of "content" within such pedagogies an unexpected yet welcome attribute. This helped to shift more stubborn biases that creative learning and teaching compromises engagement in "real" content:

[What surprised me was] Deep listening, as an activity to increase concentration rather than just as a relaxing activity; the group poem activity, as an engaging way to create group connectivity... and the preparation for Hoodwinked; the activities were interesting and very content oriented despite their dramatic focus (not that drama isn't interesting, I just expected that the activities would be a lot less focused on teaching content and historical context). (Rachel, 2012)

As Jeffrey (2008) carefully describes, creative pedagogies can (and do) incorporate relevance and meaning for students, a sense of ownership and control in the learning process, as well as innovation, whilst facilitating valued intellectual 
processes like inquiry, possibility thinking, and the engagement in problems. That our preservice teachers became aware of these qualities-together with what Sawyer (2012) describes important foundational knowledge-as an intentional aim of the storythread pedagogy is an encouraging indication of an emerging "creativity" mindset.

\section{Views of Self-as-Teacher}

Arguably the most important component of a creativity mindset for learning and teaching would entail a particular view of oneself as teacher. Jeffrey and Craft (2004) argue strongly that such a view must be based on a "learner-inclusive pedagogy" and the philosophy that teaching for creativity is less about "performance" —as Sawyer (2004) has proposed-and more about developing young people's capacity for creative thinking and behavior.

The PEEC experience had a wide-ranging impact on preservice teachers' views of "self-as-teacher." This may have been due to the immersive nature of the intervention, in which preservice teachers could see and experience first-hand the implementation of creative pedagogies by teachers who appeared "just like them":

I think that learning to teach through narrative is a valuable skill to hold. I would like to broaden the way I think about teaching and I think that the best way to do that is through experience. The content would be relevant to me due to my major in history. I think this would be a useful tool to use while teaching history to younger grades. (Erin, 2011)

I got really absorbed into the Mrs. Muddle-up "I wonder" activity and actually thought she was a real person for a moment. I found this really engaging and felt inspired that if I run Storythread Pedagogy with my own future students that they will experience something similar. (Anna, 2011)

I would definitely like to place more elements within my future teaching curriculum that will promote attentiveness and the reflective process. (Freya, 2011)

I've always thought I would struggle to communicate to young children and so I want to be a high school teacher, but after today I was surprised to learn I can communicate with them after all. (Loris, 2012) 
As the preservice teachers became more willing to reconsider their future teaching identities, they embraced the potential of creative pedagogies for prioritizing the social roles of their students over their own role as teacher (Jeffrey, 2008) as well as the significance of encouraging the creative identities of their students (Jeffrey \& Craft, 2004):

[This experience helped me to].....further break free of highly structured, traditional methods of teaching and embrace a new form a learning that is backed by some consistent research. I really want to see how this Storythread Pedagogy works and have more practice at utilizing all my senses to learn so that I can help my students do the same. (Anna, 2011)

[This experience helped me to] understand another way of teaching, and myself understand another way of learning. (Demi, 2011)

This has helped me to think about myself in terms of... being an animated extrovert, and not afraid to make a "fool" of myself (appropriately); being observant, noticing students' peaks and troughs in their learning and emotional wellbeing; being inventive and resourceful, to not be overly artistic but to create and hopefully inspire others to create amazing items-sculptures (clay, recycled goods), pictures (different textures and mediums), written (poetry and stories). (Paige, 2012)

In one sense, these revised views of "self-as-teacher" represent one of the most important qualities of a creativity mindset for teaching and learning. Craft has argued consistently for creativity to be less about what the teacher does and more about who the learner is and can be (Craft, 2003; Jeffrey \& Craft 2004). Incorporating a view of oneself as teacher that is centred on the facilitation of the learner's identity and social role (as it is emerging within Anna, Freya, and Erik's comments above) is one of the most challenging shifts for our preservice teachers to navigate ( $\mathrm{O}^{\prime}$ Brien \& Dole, 2012; O'Brien et al., 2012). 


\section{Concluding Comments: The Importance of Teachers' Perceptions of Learning, Teaching, and Pedagogy for a Creativity Mindset}

Proponents of creativity in education have argued for the place of creativity in the classroom (Burnard, 2006; McWilliam \& Haukka, 2008), proposed various types of teaching behaviors for the facilitation of creative learning (NACCCE, 1999; Sawyer, $2004,2012)$, and delineated a range of empirically evidenced practices that enable teachers to foster and build opportunities for sustained creative engagement (Jeffrey \& Craft, 2004; Jeffrey, 2008). However, in this paper I have argued that a creativity mindset is fundamental to such initiatives, and that such a mindset is underpinned by particular ways of viewing and understanding the nature of learning, teaching, and pedagogy within creatively oriented contexts.

As the analysis here aims to illustrate, a creativity mindset for teaching and learning might potentially incorporate flexible yet sophisticated perceptions of learning; a willingness to see teaching as a process of collaborative learning and the careful orchestration of multifaceted learning experiences in which the teacher is not always central; and most importantly, the kind of open-minded, open-hearted, courageous visions of self-as-teacher that casts the students into lead roles and teachers as occasional director and frequent understudy.

The challenge for teacher education is that such a mindset may be counterintuitive to the majority of people who initially choose this vocation. Adding further to this challenge is the didactic nature of university education, where our preservice teachers experience very limited models of good pedagogy, and rare glimpses of creativity as learning and teaching priorities. While the intervention reported here has some financial and organizational drawbacks, the impact on preservice teachers' growth is significant. Our challenge then, within teacher education programs, is to provide similarly immersive and extended opportunities for our students to observe and absorb the potential of creative pedagogies implemented by everyday (yet in many ways, extraordinary) teachers. 


\section{References}

Australian Curriculum, Assessment and Reporting Authority (ACARA). (2012). Shape of the Australian Curriculum: The Arts. Australian Curriculum, Assessment and Reporting Authority (ACARA). Retrieved from www. http://www.acara.edu.au/arts.html

Bell, S., Harkness, S., \& White, G. (Eds.). (2007). Storyline: past, present and future. Glasgow: University of Strathclyde.

Burnard, P. (2006). Reflecting on the creativity agenda in education. Cambridge Journal of Education, 36(3), 313-318.

Craft, A. (2003). The limits to creativity in education: dilemmas for the educator. British Journal of Educational Studies, 51(2), 113-127.

Craft, A., \& Jeffrey, B. (2008). Editorial. Creativity and performativity in teaching and learning: tensions, dilemmas, constraints, accommodations and synthesis. British Educational Research Journal, 34(4), 577-584.

Dweck, C. S. (1999). Self-theories: Their role in motivation, personality and development. Philadelphia: Psychology Press.

Education Queensland. (1994). What is storythread? Brisbane: Australia. Retrieved from http://peec.org.au/2011/10/prospec tus-2012-take-a-look/

Flick, U. (2009). An introduction to qualitative research (4th Ed): Theory, method and applications. London: Sage.

Gore, J. M., Griffiths, T., \& Ladwig, J. G. (2004). Towards better teaching: productive pedagogy as a framework for teacher education. Teaching and Teacher Education, 20(4), 375-387.

Jeffrey, B. (2008). Creative learning identities. Education 3-13: International Journal of Primary, Elementary and Early Years Education, 36(3), 253-263.

Jeffrey, B., \& Craft, A. (2004). Teaching creatively and teaching for creativity: distinctions and relationships. Educational Studies, 30(1), 77-87.
Lingard, B., Hayes, D., \& Mills, M. (2003). Teachers and productive pedagogies: Contextualising, conceptualising, utilising. Pedagogy, Culture \& Society, 11(3), 399-424.

Lortie, D. (1975). Schoolteacher: A sociological study. London: University of Chicago Press.

McWilliam, E., \& Haukka, S. (2008). Educating the creative workforce: New directions for twenty-first century schooling. British Educational Research Journal, 34(5), 651-666.

National Advisory Committee on Creative and Cultural Education (NACCCE). (1999). All our futures: creativity, culture and education. London: Department for Education and Employment.

O'Brien, M., \& Dole, S. (2012). Preservice learning and the (gentle) disruption of emerging teaching identity. In J. Faulkner et al. (Eds.). Disrupting Pedagogies and Teaching the Knowledge Society: Countering Conservative Norms with Creative Approaches. Sydney: IGI Global.

O'Brien, M., McCluskey, K., Dole, S., Mackinlay, E., \& Montes, C. (2012). Preservice teachers' experiences of tutoring Indigenous students: A study of emerging teaching identities. Conference Proceedings, Australian Teacher Education Association (ATEA) Annual Conference, 3-7 July, Adelaide, South Australia.

Organisation for Economic Cooperation and Development (OECD). (1999). The knowledge-based economy. Paris: OECD.

Renshaw, P., \& Tooth, R. (2009). Reflections on pedagogy and place: a journey into learning for sustainability through environmental narrative and deep attentive reflection. Australian Journal of Environmental Education, 25, 95-104.

Sawyer, R. K. (2004). Creative teaching: collaborative discussion as disciplined improvisation. Educational Researcher, 33(2), 12-20.

Sawyer, R. K. (2012). Explaining creativity: The science of human innovation, 2nd ed. New York: Oxford University Press. 
Schön, D. (1983). The reflective practitioner: How professionals think in practice. New York: Basic Books

Sfard, A., \& Prusak, A. (2005). Telling identities: In search of an analytic tool for investigating learning as culturally shaped activity. Educational Researcher, 34(4), 14-22.
Tooth, R., \& Renshaw, P. (2012). Storythread for environmental education. In T. Wrigley, P. Thompson, B. Lingard. (Eds.). Changing schools: Alternative ways to make a world of difference. London: Routledge.

Watt, H. M.G., \& Richardson, P. W. (2012). An introduction to teaching motivations in different countries: comparisons using the FIT-Choice scale. Asia-Pacific Journal of Teacher Education, 40(3), 185-197.

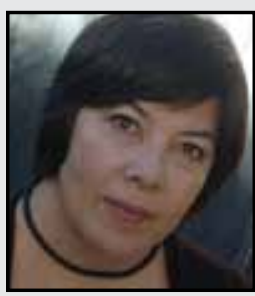

Mia O'Brien is a lecturer at the School of Education, University of Queensland, Australia. She convenes courses on creativity and learning, pedagogy and learning theories. Her research investigates the interrelationship between teaching and learning within innovative pedagogical contexts, and she is particularly interested in the implementation of positive psychologies, new media and the creative arts, and inquiry and dialogue in learning contexts. Her recent publications focus on the professional learning and identities of preservice teachers, and with whom she shares a passionate interest in the integration of creativity in pedagogical practice. She is also a keen singer-songwriter and avid fan of early swing, jazz, and gypsy music.

\section{LINKTO:}

http://peec.org.au/

http://www.uq.edu.au/uqresearchers/researcher/obrienm.html

http://positivepedagogy.net/ 